\title{
CLUSTERING FILE TERDISTRIBUSI
}

\author{
Yenni Astuti, Muhammad Harikem Ali Akbar \\ Jurusan Teknik Informatika \\ Sekolah Tinggi Teknologi Adisutjipto Yogyakarta \\ informatika@stta.ac.id
}

\begin{abstract}
The development of information technology is increasing at this time, certainly makes it easy for users of the technology itself One of them in transferring files in a distributed manner, there are many types of files that make it difficult admin in selecting and classifying the file and then will be distributed to each - its own servers. By creating a new system that will facilitate Clustering distributed file an admin in file transfer without having to select the files to be distributed, because the system will automatically read from the file types that will be distributed on its own servers each.
\end{abstract}

Keywords: Clustering, files, distributed systems.

\section{Pendahuluan}

Perkembangan teknologi informasi yang semakin maju di saat ini, tentunya tidak luput dari kerja keras para pecinta teknologi, yang saling bersaing untuk menciptakan teknologi yang baru, agar dapat memberikan kemudahan serta manfaat bagi pengguna teknologi informasi saat ini. Seperti pada sebuah sistem pengunggah (upload) yang bias menyebarkan file yang di-upload sesuai dengan server-nya masing-masing tanpa harus menentukan server tujuan file yang akan di-upload terlebih dahulu. Ketika file sudah terkelola dengan teratur di dalam sebuah mesin penyimpanan atau disebut dengan server, tentunya memberikan kemudahan bagi pengguna dan pemakai informasi yang di-upload tersebut. Pengelompokan file dari server induk (server moderator) ke slave server yang menggunakan system terdistribusi tentunya menberikan kemudahan terhadap admin untuk mengelola data di dalamnya dan juga memberikan kemudahan bagi client dalam mengambil data yang di-upload oleh admin ke server.

Dengan berjalannya waktu, manusia membutuhkan solusi untuk mempermudah dalam hal penggungah (upload) dan unduh (download). Oleh karena itu solusinya adalah membuat system yang bias mengelompokkan (Clustering) file ke server-nya masing-masing berdasarkan tipe dari file yang akan di-upload tersebut. Fileyang berada pada server-nya masing-masing tentunya akan memudahkan pengguna dalam mengelola data yang tersimpan di dalamnya serta menghemat waktu yang dibutuhkan dalam upload. Menggunakan system terdistribusi tentunya memberikan solusi yang efektif dalam pengiriman data ke dalam server tanpa memikirkan tempat yang saling berjauhan dan bias diakses di manapun dan kapanpun selagi terhubung dengan jaringan Internet. Pengembangan sistem terdistribusi yang bias mengelompokkan file di dalam server masing-masing, yang berdasarkan tipe file-nya, tentunya akan memudahkan bagi admin dalam pengolahan data yang dikirim di dalamnya, sehingga tidak memerlukan banyak system untuk pengiriman sebuah file terhadap server-nya masing-masing. 


\section{Metodologi Penelitian}

\subsection{Pengertian Clustering}

Clustering merupakan pengelompokan sekumpulan objek sehingga bisa berada dalam satu kelompok yang sama yang disebut cluster. Objek-objek dalam sebuah cluster memiliki tingkat kemiripan yang tinggi. Dan antar cluster memiliki tingkat kemiripan yang rendah. Clustering merupakan teknik yang umum digunakan dalam menganalisa data statistik untuk berbagai bidang, misalnya machine learning, pattern analysis, image analysis, information retrieval dan bio informatika.

Analisa cluster bisa dilakukan dengan beberapa algoritma dengan kelebihan dan kekurangan masing-masing. Sebuah algoritma bisa membentuk cluster yang detil dan akurat, namun memiliki kekurangan karena memerlukan resource komputer yang sangat tinggi dan hal ini berlaku kebalikan untuk jenis algoritma yang lain. Tipe dokumen yang di-cluster juga merupakan salah satu faktor untuk menentukan algoritma clustering yang digunakan.

\subsection{Perancangan Arsitektur Sistem}

Media transmisi sistem yang dibangun menggunakan jaringan internet yang terkoneksi secara langsung antar komputer server dan komputer client, tanpa menggunakan kabel, sehingga client dapat mengakses server dimanapun dan kapanpun selagi komputer terhubung dengan jaringan internet. Terdapat satu buah komputer yang dijadikan sebagai komputer server moderator danlima server cluster yang digunakan serta komputer client. Komputer moderator berfungsi untuk mengirimkan file terhadap lima server cluster, file yang dikirim melalui komputer moderator akan secara otomatis dipisahkan oleh sistem, dimana sistem membaca setiap tipe file yang akan diupload oleh admin komputer moderator yang selanjutnya didistribusikan ke server cluster-nya masing-masing. Adapun server cluster yang digunakan di antaranya yaitu server suara yang berfungsi untuk menampung tipe file dari suara, server gambar yang berfungsi untuk menampung tipe file dari gambar, server dokumen yang berfungsi untuk menampung tipe file dari dokumen, server video yang berfungsi untuk menampung tipe file dari video dan server lain yaitu berfungsi untuk menampung tipe file selain dari tipe file dari suara, gambar, dokumen, dan video. Untuk membuka dan mengakses masing-masing server, client bisa mengakses dengan nama domain masing-masing server. Untuk nama domain server gambar yaitu dengan nama tintin.site50.net/files, server dokumen radi.net76.netfiles, server suara dudeee.site90.com/files, server video speedy.site88.netffiles dan server lain dengan nama domain aliac.net46.net/files. 


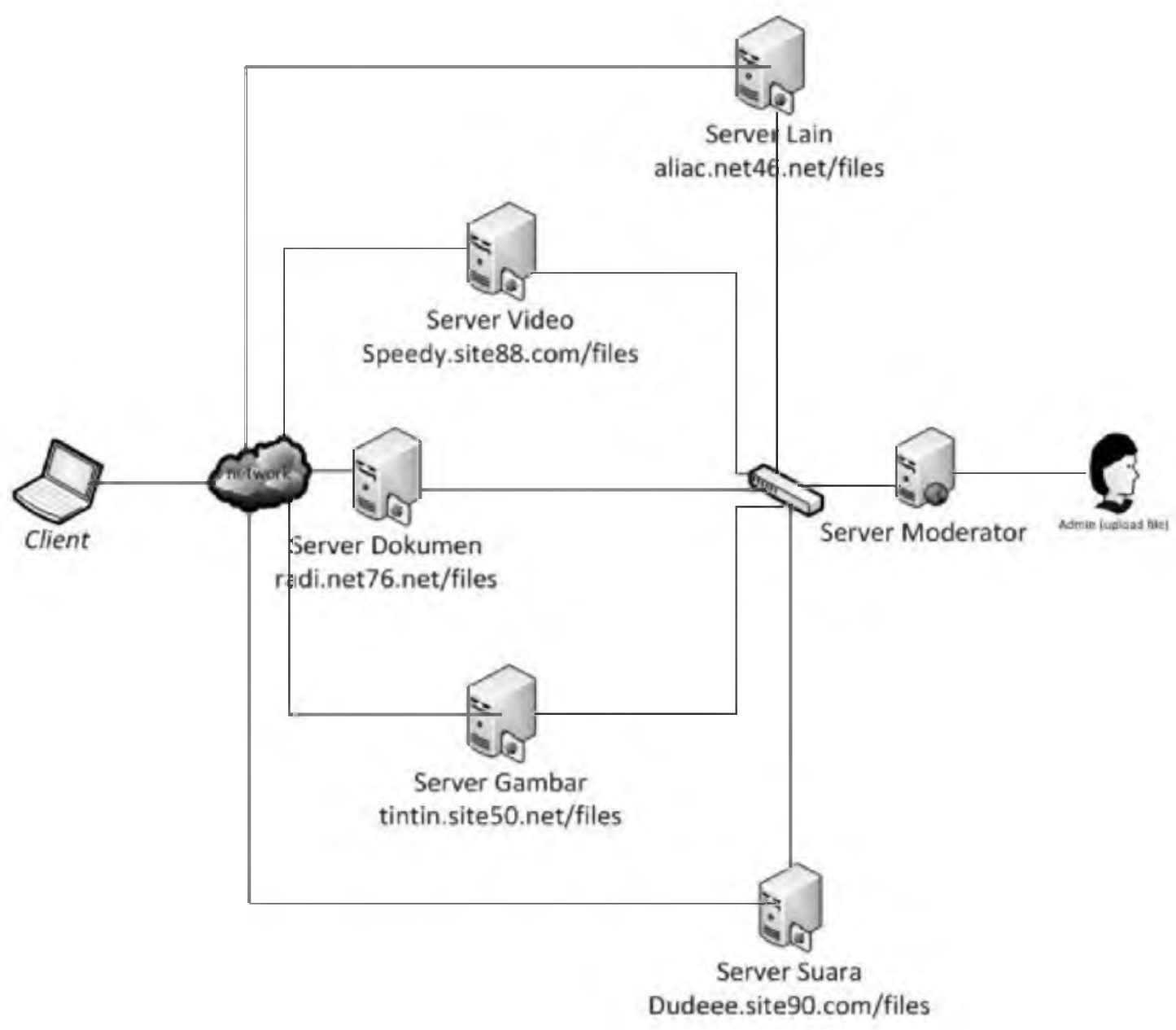

Gambar 1 Perancangan Arsitektur Sistem

Pengiriman, pengelompokan dan pengambilan file yang berasal dari computer pengguna dilakukan melalui FTP server. Sehingga file yang akan di-uploaddan di-download berada pada FTP server. Bedasarkan pada pengidentiikasian sistem, bahwa dalam system ini hanya memiliki satu aktor atau yang memiliki username sendiri. File yang akan di-download melalui komputer pengguna terlebih dahulu harus dikirim ke FTP server agar dapat langsung di-download oleh client di manapun dan kapanpun selagi terkoneksi dengan jaringan internet. Dari ilustrasi tersebut dapat diketahui obyek-obyek yang terlibat beserta atribut dan operasi setiap obyeknya, obyek-obyek ini kemudian dibangun dalam diagram high-level-class, seperti pada gambar 2 berikut: 


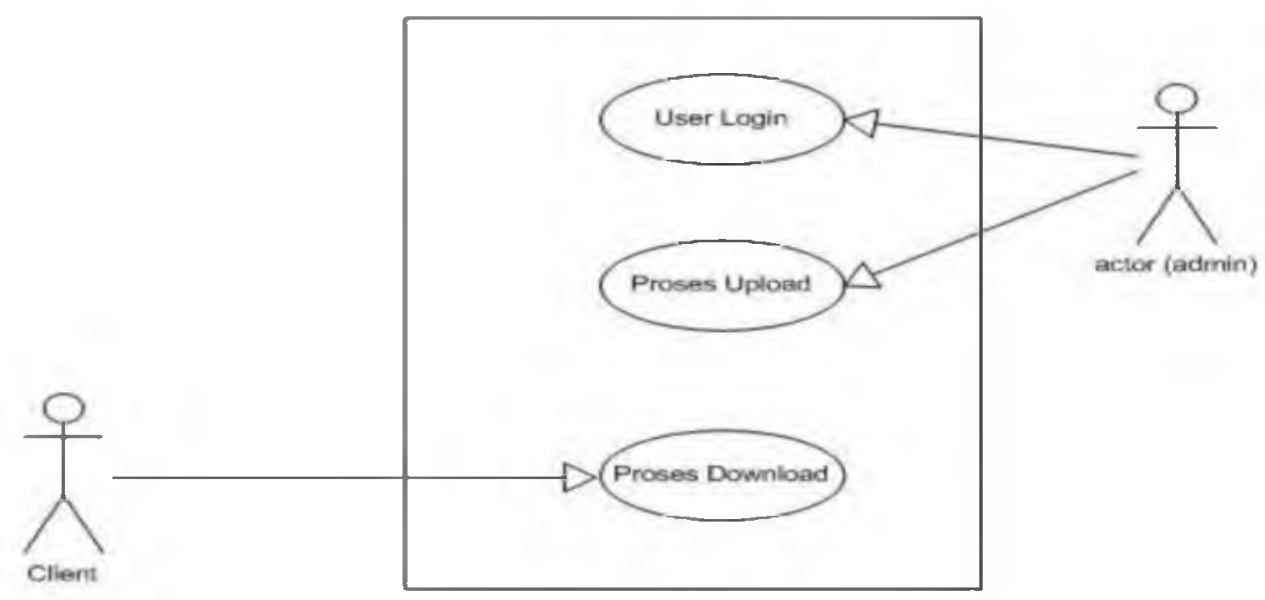

Gambar 2 Diagram High-level-use-case

\subsubsection{Flowchart System}

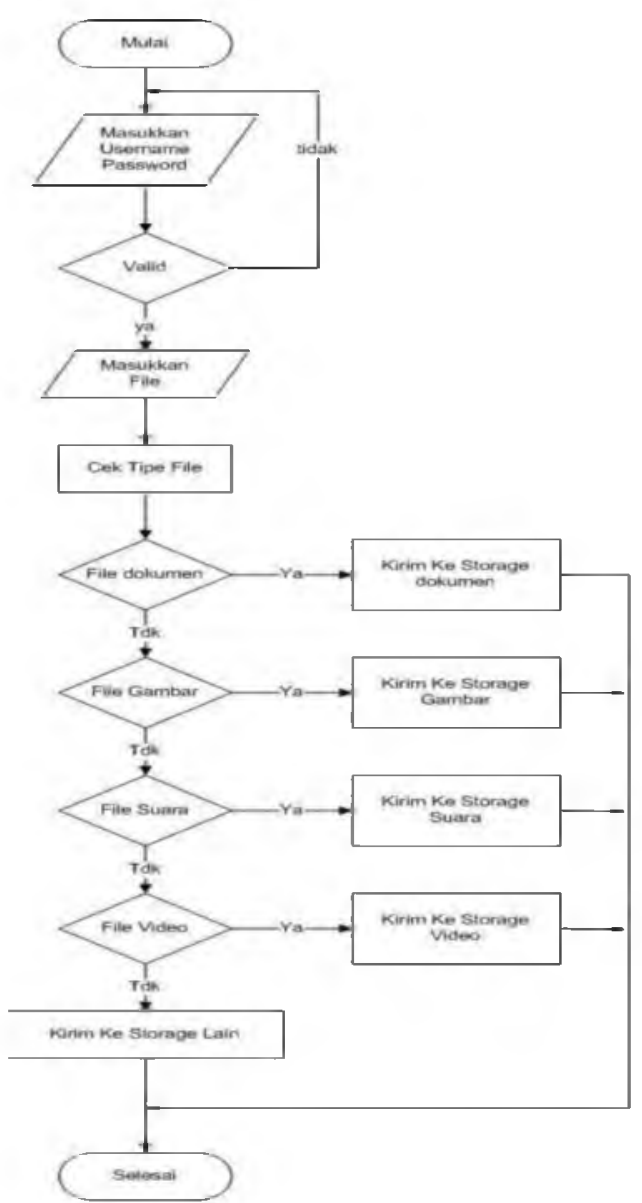

Gambar 3 Flowchart System Upload File

Dari gambar 3 Flowchart System Upload File menjelaskan bahwa, pertama admin melakukan proses login setelah berhasil login seorang admin melakukan upload file, dan kemudian system akan melakukan pengecekan pada file yang di-upload jika file yang di-upload merupakan tipe dari file gambar, video, dokumen, dan suara, makan file tersebut akan menuju server masing-masing, dan jika bukan dari keempat dari tipe file tersebut maka file akan berada pada server lain. 


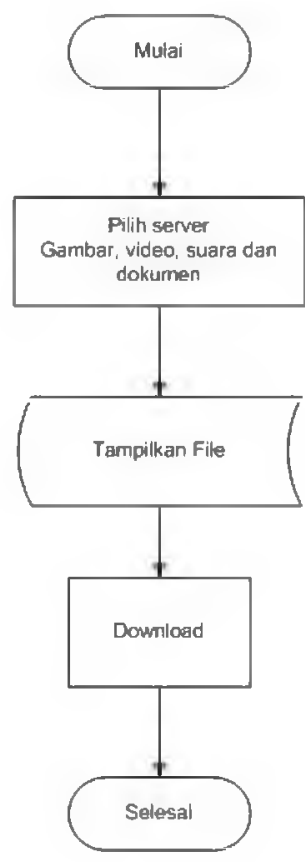

Gambar 4 Flowchart System Download File

Dari gambar 4 Flowchart System Upload File menjelaskan client yang akan men-download file, akan memilih terlebih dahulu server dari file yang akan di-download. Setelah memilih salah satu dari server maka file dari server tersebut bisa untuk di-download.

\section{Hasil Dan Pembahasan}

Uji coba sistem ini dilakukan cukup mengandalkan jaringan internet dimanapun dan kapanpun selagi terkoneksi dengan internet baik menggunakan modem untuk akses internet maupun jaringan WIFI. Uji coba yang dilakukan yaitu meng-upload sejumlah file untuk memastikan file berada pada server sluster-nya masing-masing, serta download file yang telah di-upload pada server-nya masing-masing.

\subsection{Uji Coba Upload File}

Upload file yang dilakukan yaitu dengan menggunakan komputer moderator karena komputer moderator yang hanya memiliki andil untuk melakukan upload file. 


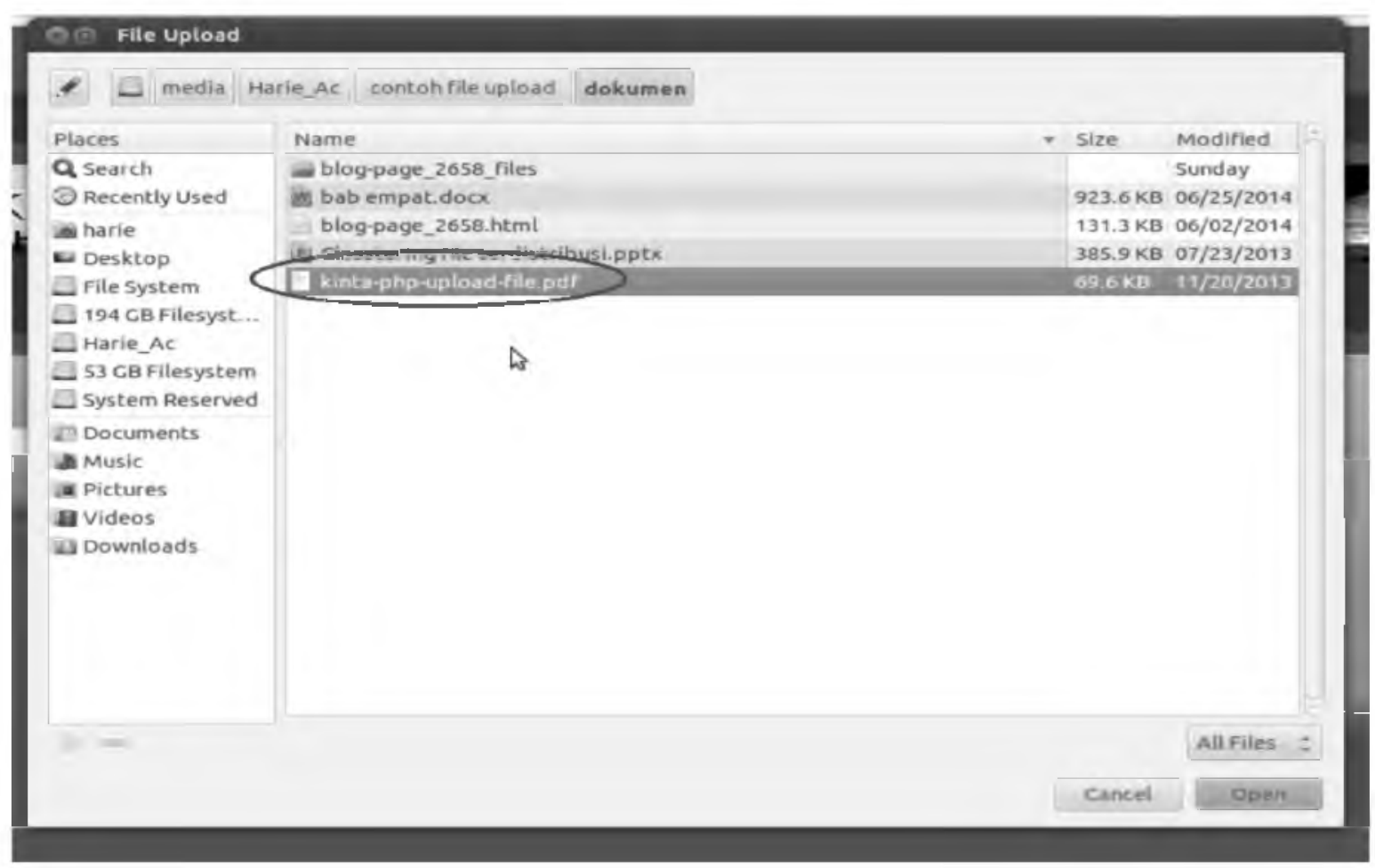

\section{Gambar 5 upload file}

Gambar 5 merupakan contoh upload dari salah satu tipe file dari dokumen yang dilakukan melalui komputer server moderator yang terhubung dengan jaringan internet.

INFO FILE

Table Data Indexes Model Constraints Grants Statistics UIDefaults Triggers Dependencies SQL

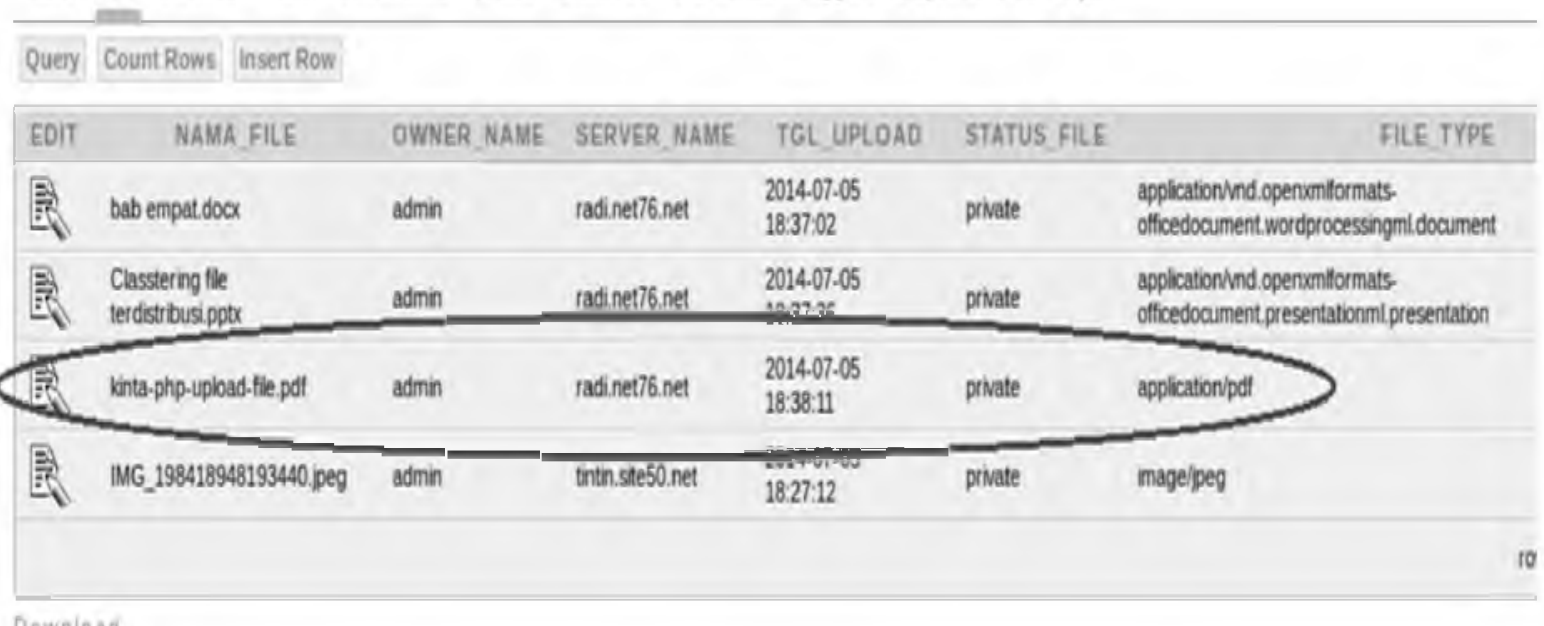

Gambar 6 Hasil Record Pada Database

Gambar 6 merupakan hasil record di dalam database file berada pada lingkaran yang berwarna merah merupakan hasil upload dari komputer moderator yang telah dilakukan pada gambar 5 sebelumnya. 


\subsection{Uji Coba Download File}

Proses download bisa dilakukan oleh client tanpa harus memiliki hak akses untuk melakukan download file tersebut. Client cukup mengetahui domain yang sudah ditentukan oleh komputer moderator atau pembuat sistem untuk melakukan download cukup mengandalkan jaringan internet dan mengakses nama domain dari server yang diinginkan maka download bisa dilakukan. Berikut contoh download file yang sudah di-upload oleh komputer moderator sebelumnya.

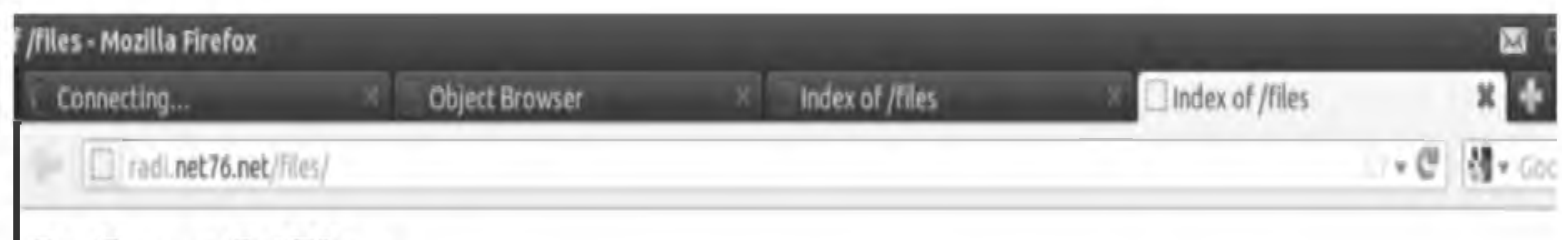

\section{Index of /files}

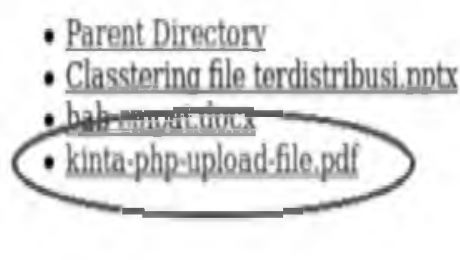

\subsection{Pembahasan}

Untuk mendapatkan hasil perbandingan kecepatan pada saat download file maka dilakukan uji fungsi antara server file yang di dalamnya sudah di cluster dengan server file yang tidak di cluster. Berikut dipaparkan dalam bentuk table perbandingan.

Tabel 1 Perbandingan Download file

\begin{tabular}{|l|l|l|l|l|l|}
\hline NO & Namaserver & Namafile & Size & Kecepatan rata-rata & Waktuselesai \\
\hline 1 & Campur & Bab 1vv.docx & $5.3 \mathrm{MB}$ & $10.000 \mathrm{~KB} / \mathrm{sec}$ & $9 \min 4 \sec$ \\
\hline 2 & Dokumen & Bab 1vv.docx & $5.3 \mathrm{MB}$ & $10.000 \mathrm{~KB} / \mathrm{sec}$ & 8 min 4 sec \\
\hline
\end{tabular}

Pada table 1 hasil pengujian yang diperoleh untuk perbandingan antara kedua server campur dan server cluster maka terdapat selisih waktuya itu berkisar 1 min 3 sec dengan kecepatan rata-rata $10.000 \mathrm{~KB} / \mathrm{sec}$.

Dari hasil semua percobaan dapat dianalisa dari implementasi dan simulasi percobaan adalah tentang proses mekanisme kerja dari sistem secara keseluruhan. Adapun hasil dari percobaan pada sistem yang telah dilakukan sebelumnya dapat dilihat pada tabel 2 berikut:

Tabel 2 Hasil Uji Sistem

\begin{tabular}{|l|l|l|l|c|}
\hline No & \multicolumn{1}{|c|}{ Nama File } & \multicolumn{1}{|c|}{ Tipe File } & \multicolumn{1}{c|}{ Hasil Upload } & Keterangan \\
\hline 1 & Clusstering.pptx & Dokumen & Radi.net76.net & Berhasil \\
\hline 2 & Kampus.tif & Gambar & Tintin.site50.net & Berhasil \\
\hline 3 & Destop.fly & Video & Speedy.site88.net & Berhasil \\
\hline 4 & Aline.amr & Suara & Dudeee.site90.com & Berhasil \\
\hline 5 & Dsc01231.pcx & Gambar & Tintin.site50.net & Berhasil \\
\hline 6 & Drawing8.vsd & Dokumen & Radi.net76.net & Berhasil \\
\hline 7 & Movie.wmv & Video & Speedy.site88.net & Berhasil \\
\hline
\end{tabular}




\begin{tabular}{|c|c|c|c|c|}
\hline 8 & mapping.dotx & Dokumen & Radi.net76.net & Berhasil \\
\hline 9 & panorama.gif & Gambar & Tintin.site50.net & Berhasil \\
\hline 10 & BondanPrakoso - & Suara & Dudeee.site90.com & Berhasil \\
\hline 11 & film.avi & Video & Speedy.site88.net & Berhasil \\
\hline 12 & Wajah.jpg & Gambar & Tintin.site 50.net & Berhasil \\
\hline 13 & Hiburan.mpg & Video & Speedy.site88.net & Berhasil \\
\hline 14 & Stta.bmp & Gambar & Tintin.site.50.net & Berhasil \\
\hline 15 & $\begin{array}{l}\text { Ben E King - Stand } \\
\text { By Me.mmf }\end{array}$ & Suara & Dudee.site90.com & Berhasil \\
\hline 16 & Ultah.vob & Video & Speedy.site88.net & Berhasil \\
\hline 17 & Bab empat.dock & Dokumen & Radi.net76.net & Berhasil \\
\hline 18 & Dua.tiga & Gambar & Tintin.site50.net & Berhasil \\
\hline 19 & Keramaian.MOV & Video & Speedy.site88.net & Berhasil \\
\hline 20 & 14 where.m4a & Suara & Dudeee.site90.com & Berhasil \\
\hline 21 & Camp.mp4 & Vidio & Speedy.site88.net & Berhasil \\
\hline 22 & Gambar.png & Gambar & Tintin.site 50.net & Berhasil \\
\hline 23 & Ewel tugas.rtf & Dokumen & Radi.net76.net & Berhasil \\
\hline 24 & Laguislami & Suara & Dudeee.site90.com & Berhasil \\
\hline 25 & Konser.3gp & Video & Speedy.site88.net & Berhasil \\
\hline 26 & Data.xlsx & Dokumen & Radi,net76.net & Berhasil \\
\hline 27 & BARA-.MP3 & Suara & Dudeee.site90.com & Berhasil \\
\hline 28 & Harie.txt & Dokumen & Radi.net76.net & Berhasil \\
\hline 29 & $\begin{array}{l}\text { Lagumengejar } \\
\text { mimpi.m3u }\end{array}$ & Suara & Dudeee.site90.com & Berhasil \\
\hline 30 & Kinta-php.pdf & Dokumen & Radi.net76.net & Berhasil \\
\hline 31 & FIRMAN .wma & Suara & Dudeee.site90.com & Berhasil \\
\hline 32 & 7crack.rar & Lain & Aliac.net46.net & Berhasil \\
\hline
\end{tabular}

\section{Penutup}

\subsection{Kesimpulan}

Dari hasil uji coba yang telah dilakukan dapat ditarik beberapa kesimpulan:

1. Sistem clustering file terdistribusi telah berhasil digunakan untuk upload, dimana file terlebih dahulu di-filter oleh sistem untuk dikelompokkan berdasarkan tipe file-nya masing-masing.

2. Jumlah server yang digunakan adalah satu yang bertindak sebagai server moderator dan lima slave server yang masing-masing bertindak sebagai server dari gambar, suara, dokumen, video dan lain.

3. File yang telah berada di dalam server bisa diakses secara real time oleh client kapanpun dan di manapun selagi terhubung dengan jaringan internet.

4. Dari hasil uji fungsi yang dilakukan bahwa antara server campur dan yang di cluster maka terdapat selisih waktu download yang lebih diunggulkan oleh server cluster dengan menggunakan kecepatan yang sama dan kecepatan dari internet yang digunakan mempengaruhi hasil akhir download.

\subsection{Saran}

Adapun beberapa saran diperoleh dari tugas akhir ini adalah :

1. Tampilan dari sistem Clustering File terdistribusi dirancang lebih apik dan lebih menarik lagi.

2. Pada sisi server menggunakan ruang kapasitas yang lebih besar jika akan diterapkan pada sebuah kantor maupun sebuah perusahaan yang berskala besar. 
3. Menambahkan auto rename pada sistem yang akan di-upload jika pada server sudah ada file yang sama.

4. Menambahkan server untuk file yang bertipe lainnya jika dibutuhkan.

\section{Daftar Pustaka}

Kadir, Abdul. 2009. Membuat Aplikasi Web Dengan PHP + Databse MySQL.Yogyakarta. Andi Offset.

Lysy C, Moleong. 2013. Implementasi Cluster Computing Untuk Render Animasi Jurusan Teknik Elektro-FT. UNSRAT,. Manado.

Munandar. Ai Tb. 2013. Clustering Data Nilai Mahasiswa Untuk Pengelompokan Kosentrasi Jurusan Menggunakan Fuzzy Cluster Mean. Banten. Jurnal Teknik Informatika Serang Raya Banten.

Samsiar Evara. 2008. Belajar Sendiri Administrasi Database Oracle 10g. Jakarta. Elex Media Komputido.

Sutedjo, Budi. 2003. Konsep \& Aplikasi Client Server dan Sistem Terdistribusi. Yogyakarta. Andi Offset.

Syafrizal, Melwin. 2005. Pengantar Jaringan Komputer. Yogyakarta. Andi Offset.

Ursula Maier dan Georg Stellner. 2008. Distributed Resource 
Yenni Astuti. Muhammad Harikem Ali Akbar. 